\title{
Analisis Hubungan Persepsi tentang Mutu Pelayanan Rekam Medis dengan Tingkat Kepuasan di Rumah Sakit
}

\section{Analysis of the Relationship between Perceptions of the Quality of Medical Record Services and the Level of Satisfaction in Hospitals}

\author{
Puput Sugiarto ${ }^{1}$ \\ Dwi Wahyu Aprilistiyani2 ${ }^{2}$ \\ Syafira Atikah Yudianti ${ }^{3}$
}

\author{
1,2,3) Jurusan Rekam Medis dan Informasi Kesehatan ; Poltekkes Kemenkes Semarang \\ Jl. Tirto Agung, Pedalangan, Banyumanik, Semarang \\ Email : puputsugiartormik@gmail.com
}

\begin{abstract}
Hospitals must be able to improve the quality of services to maintain patient interest, one of which is improving the quality of medical records. Based on the author's initial survey that at the Ungaran District Hospital research has not been conducted on patient satisfaction regarding the quality of medical record services. To measure a service quality is to know perceptions about the service from the eyes of a consumer or customer. This patient's perception is very important because satisfied patients will adhere to treatment and want to come back for treatment. The purpose of this study was to determine the analysis of the relationship between patients' perceptions about the quality of medical record services with the level of patient satisfaction at Ungaran District Hospital. This study uses a descriptive correlative research method using a survey approach. The results of this study using the chi square test $(\mathrm{p}<0.05)$ showed that there was not relationship between perception, especially reliability, assurance, and empathy about the quality of medical record services with the level of patient satisfaction with a $\mathrm{p}$ value of reliability of 0.116 ; guarantee 0.191 ; empathy of 0.058 . There is relationship between perception, especially responsiveness and tangible about the quality of medical record services with the level of patient satisfaction. In the reliability variable, it is necessary to maintain and improve the aspects of the quality of service from officers to patients. In the tangible variable, it is necessary to improve the ability and attitude of officers in serving patients. In the empathy variable, the role of officers who understand patients is very important.
\end{abstract}

Keyword: Perception; Satisfaction; Quality of Service; Medical Record

\begin{abstract}
Abstrak
Rumah sakit harus mampu meningkatkan kualitas pelayanannya untuk mempertahankan minat atau ketertarikan pasien salah satunya peningkatan kualitas pelayanan rekam medis. Berdasarkan survey awal penulis bahwa di RSUD Ungaran belum dilakukan penelitian tentang kepuasan pasien terkait mutu pelayanan rekam medis. Untuk mengukur sebuah kualitas pelayanan adalah dengan mengetahui persepsi tentang pelayanan tersebut dari kaca mata seorang konsumen atau pelanggan. Persepsi pasien ini sangat penting karena pasien yang puas akan mematuhi pengobatan dan bersedia datang berobat kembali. Tujuan penelitian ini adalah mengetahui analisis hubungan persepsi pasien tentang mutu pelayanan rekam medis dengan tingkat kepuasan pasien di RSUD Ungaran. Penelitian ini menggunakan metode penelitian deskriptif korelatif dengan menggunakan pendekatan survey. Hasil penelitian ini menggunakan uji chi square $(\mathrm{p}<0,05)$ diperoleh hasil tidak ada hubungan antara persepsi khususnya keandalan, jaminan, dan empati tentang mutu pelayanan rekam medis dengan tingkat kepuasan pasien dengan nilai $p$ value keandalan 0,116; jaminan 0,191; empati 0,058. Ada hubungan antara persepsi khususnya ketanggapan dan bukti langsung tentang mutu pelayanan rekam medis dengan tingkat kepuasan pasien. Pada variabel keandalan perlu mempertahankan dan
\end{abstract}


meningkatkan aspek kualitas layanan petugas kepada pasien. Pada variabel bukti langsung perlu meningkatkan kemampuan dan sikap petugas dalam melayani pasien. Pada bagian variabel empati peran petugas yang memahami pasien sangat penting.

Kata Kunci: Persepsi; Kepuasan; Mutu Pelayanan; Rekam Medis

\section{Pendahuluan}

Suatu rumah sakit tidak hanya memiliki fungsi sebagai tempat kegiatan kuratif, namun berfungsi juga sebagai tempat untuk meningkatkan status kesehatan individu, sehingga kualitas kesehatan dan hidup masyarakat Indonesia juga meningkat. Rumah sakit sebagai institusi pelayanan kesehatan baik pemerintah maupun swasta dituntut untuk selalu melakukan perbaikan dan penyempurnaan agar menghasilkan pelayanan berkualitas dan bermanfaat bagi masyarakat.

Salah satu upaya untuk mewujudkan pelayanan yang berkualitas di rumah sakit adalah meningkatkan mutu pendokumentasian rekam medis. Pelayanan kesehatan yang telah diberikan kepada pasien harus terdokumentasikan ke dalam rekam medis, baik pelayanan rawat jalan, rawat inap, maupun gawat darurat. Rekam medis yang dibuat harus berisi data yang lengkap dan akurat agar terwujud kepuasan pasien dalam memberikan pelayanan rekam medis. Pasien mempunyai hak untuk mengetahui catatan atau riwayat sakit yang pernah dideritanya. Pengetahuan pasien mengenai riwayat penyakit yang pernah diderita dapat meningkatkan kesadaran atau kewaspadaan diri terhadap penyakit yang sama di masa yang akan datang.

$$
\text { Untuk mengetahui kualitas }
$$

pelayanan rekam medis terhadap pasien, perlu adanya upaya penelitian mengenai kepuasan pasien terhadap mutu pelayanan rekam medis dan persepsi pasien tentang mutu pelayanan rekam medis. Berdasarkan studi pendahuluan penulis bahwa di RSUD Ungaran belum dilakukan penelitian tentang analisis hubungan persepsi pasien tentang mutu pelayanan rekam medis dengan tingkat kepuasan pasien. Penelitian sebelumnya yang pernah dilakukan adalah penelitian tentang analisis kepuasan pasien rawat jalan terhadap pelayanan pendaftaran rawat jalan di RSUD Ungaran. Hasil penelitian sebelumnya diperoleh informasi kepuasan pasien terhadap pelayanan pendaftaran rawat jalan adalah sebesar $75,5 \%$.

Mutu pelayanan rekam medis tidak hanya dilihat dari pendaftaran rawat jalan saja, namun bagian-bagian dari Instalasi Rekam Medis yang memberikan pelayanan langsung kepada pasien yang meliputi pendaftaran rawat jalan, pendaftaran rawat inap, pendaftaran UGD, pelayanan distribusi rekam medis, dan pelepasan informasi perlu mendapat perhatian. Oleh karena itu, penelitian ini bertujuan untuk melakukan analisis hubungan persepsi pasien tentang mutu pelayanan rekam medis dengan tingkat kepuasan pasien di RSUD Ungaran.

\section{Metode}

Jenis penelitian ini adalah deskriptif korelatif dengan pendekatan survey mengenai hubungan persepsi pasien tentang mutu pelayanan rekam medis dengan tingkat kepuasan pasien. Variabel dalam penelitian ini meliputi variabel independen yaitu persepsi tentang mutu pelayanan rekam medis yang meliputi dimensi mutu dijelaskan terhadap variabel dependen yaitu kepuasan pasien.

Penelitian ini dilakukan terhadap 100 responden yaitu pasien yang mendapatkan pelayanan rekam medis baik dalam pelayanan rawat inap, rawat jalan dan gawat darurat di RSUD Ungaran dengan memberikan kuesioner agar responden dapat memberikan penilaian terhadap pelayanan rekam medis sesuai dengan persepsi dan kepuasan kenyataan yang ada berdasarkan 5 aspek penilaian. Lima aspek penilaian tersebut meliputi aspek tangible (bukti langsung), reliability (keandalan), 
responsiveness (ketanggapan), assurance (jaminan), dan empathy (perhatian).

Lokasi penelitian di Instalasi Rekam Medis yang meliputi bagian pendaftaran pasien rawat jalan, pendaftaran rawat inap, pendaftaran UGD, pelayanan distribusi rekam medis, dan pelepasan informasi RSUD Ungaran. Waktu pelaksanaan penelitian pada bulan September - November 2018. Sampel yang diambil sebanyak 100 responden dengan perhitungan slovin. Metode pengumpulan data melalui pembagian kuesioner kepada responden.

Analisa data pada penelitian ini menggunakan analisa univariat dan bivariat. Analisa univariat dilakukan pada tiap variabel dari hasil penelitian dari keandalan, ketanggapan, jaminan, empati, dan bukti langsung. Analisa bivariat menggunakan uji chi square untuk mengetahui korelasi antara variabel bebas dan variabel terikat. Signifikansi uji chi square menggunakan derajat kepercayaan 95\% ( $\alpha=5 \%$ ). Jika Pvalue $\leq 0,05$ maka hipotesis alternatif (Ha) diterima atau hipotesis null (Ho) ditolak yang menunjukkan ada hubungan antara variabel independen dengan variabel dependen.

\section{Hasil dan Pembahasan}

\section{Analisis Univariat}

Analisis univariat dilakukan melalui pembagian kuesioner yang menilai tentang persepsi dan kepuasan responden terhadap pelayanan rekam medis. Lima aspek penilaian tersebut meliputi aspek tangible (bukti langsung), reliability (keandalan), responsiveness (ketanggapan), assurance (jaminan), dan empathy (perhatian).

Berikut ini tabel distribusi pada masingmasing aspek penilaian:

Tabel 1.

Distribusi Persepsi Keandalan

\begin{tabular}{ccc}
\hline Keandalan & Jumlah & Persentase (\%) \\
\hline Setuju & 87 & 87 \\
Tidak Setuju & 13 & 13 \\
\hline Jumlah & $\mathbf{1 0 0}$ & $\mathbf{1 0 0}$ \\
\hline
\end{tabular}

Tabel 2.

Distribusi Kepuasan Keandalan

\begin{tabular}{ccc}
\hline Keandalan & Jumlah & Persentase (\%) \\
\hline Puas & 90 & 90 \\
Tidak Puas & 10 & 10 \\
\hline Jumlah & $\mathbf{1 0 0}$ & $\mathbf{1 0 0}$ \\
\hline
\end{tabular}

Tabel 3.

Distribusi Persepsi Ketanggapan

\begin{tabular}{ccc}
\hline Ketanggapan & Jumlah & $\begin{array}{c}\text { Persentase } \\
\mathbf{( \% )}\end{array}$ \\
\hline Setuju & 92 & 92 \\
Tidak Setuju & 8 & 8 \\
\hline Jumlah & $\mathbf{1 0 0}$ & $\mathbf{1 0 0}$ \\
\hline
\end{tabular}

Tabel 4.

Distribusi Kepuasan Ketanggapan

\begin{tabular}{ccc}
\hline Ketanggapan & Jumlah & Persentase (\%) \\
\hline Puas & 95 & 95 \\
Tidak Puas & 5 & 5 \\
\hline Jumlah & $\mathbf{1 0 0}$ & $\mathbf{1 0 0}$ \\
\hline
\end{tabular}

Tabel 5.

Distribusi Persepsi Jaminan

\begin{tabular}{ccc}
\hline Jaminan & Jumlah & Persentase (\%) \\
\hline Setuju & 100 & 100 \\
Tidak Setuju & 0 & 0 \\
\hline Jumlah & $\mathbf{1 0 0}$ & $\mathbf{1 0 0}$ \\
\hline
\end{tabular}

Tabel 6.

Distribusi Kepuasan Jaminan

\begin{tabular}{ccc}
\hline Jaminan & Jumlah & Persentase (\%) \\
\hline Puas & 97 & 97 \\
Tidak Puas & 3 & 3 \\
\hline Jumlah & $\mathbf{1 0 0}$ & $\mathbf{1 0 0}$ \\
\hline
\end{tabular}

Tabel 7.

Distribusi Persepsi Empati

\begin{tabular}{ccc}
\hline Empati & Jumlah & Persentase (\%) \\
\hline Setuju & 94 & 94 \\
Tidak Setuju & 6 & 6 \\
\hline Jumlah & $\mathbf{1 0 0}$ & $\mathbf{1 0 0}$ \\
\hline
\end{tabular}

Tabel 8.

Distribusi Kepuasan Empati

\begin{tabular}{ccc}
\hline Empati & Jumlah & Persentase (\%) \\
\hline Puas & 95 & 95 \\
Tidak Puas & 5 & 5 \\
\hline Jumlah & $\mathbf{1 0 0}$ & $\mathbf{1 0 0}$ \\
\hline
\end{tabular}


Tabel 9.

Distribusi Persepsi Bukti Langsung

\begin{tabular}{ccc}
\hline $\begin{array}{c}\text { Bukti } \\
\text { Langsung }\end{array}$ & Jumlah & Persentase (\%) \\
\hline Setuju & 89 & 89 \\
Tidak Setuju & 11 & 11 \\
\hline Jumlah & $\mathbf{1 0 0}$ & $\mathbf{1 0 0}$ \\
\hline
\end{tabular}

Tabel 10.

Distribusi Kepuasan Bukti Langsung

\begin{tabular}{ccc}
\hline $\begin{array}{c}\text { Bukti } \\
\text { Langsung }\end{array}$ & Jumlah & Persentase (\%) \\
\hline Puas & 94 & 94 \\
Tidak Puas & 6 & 6 \\
\hline Jumlah & $\mathbf{1 0 0}$ & $\mathbf{1 0 0}$ \\
\hline
\end{tabular}

\section{Aspek Keandalan}

Hasil uji univariat keandalan diperoleh bahwa sebanyak $87 \%$ responden menyatakan persepsi keandalan setuju dan $13 \%$ tidak setuju. Hasil uji univariat keandalan diperoleh bahwa sebanyak $90 \%$ responden menyatakan puas dan $10 \%$ responden menyatakan tidak puas.

\section{Aspek Ketanggapan}

Variabel ketanggapan diperoleh bahwa sebanyak $92 \%$ responden menyatakan persepsi ketanggapan setuju dan 8\% responden menyatakan tidak setuju terhadap kualitas pelayanan rekam medis. Variabel ketanggapan diperoleh bahwa sebanyak 95\% responden menyatakan puas dan 5\% responden menyatakan tidak puas.

\section{Aspek Jaminan}

Variabel jaminan diperoleh bahwa sebanyak $100 \%$ responden menyatakan persepsi jaminan setuju dan $0 \%$ responden menyatakan tidak setuju terhadap kualitas pelayanan rekam medis. Variabel jaminan diperoleh bahwa sebanyak $97 \%$ responden menyatakan puas dan 3\% responden menyatakan tidak puas.

\section{Aspek Empati}

Variabel empati diperoleh bahwa sebanyak $94 \%$ responden menyatakan persepsi empati setuju dan $6 \%$ responden menyatakan tidak setuju terhadap kualitas pelayanan rekam medis. Variabel empati diperoleh bahwa sebanyak 95\% responden menyatakan puas dan 5\% responden menyatakan tidak puas.

\section{Aspek Bukti Langsung}

Variabel bukti langsung diperoleh bahwa sebanyak $89 \%$ responden menyatakan persepsi bukti langsung setuju dan 11\% responden menyatakan tidak setuju terhadap kualitas pelayanan rekam medis. Variabel bukti langsung diperoleh bahwa sebanyak $94 \%$ responden menyatakan puas dan $6 \%$ responden menyatakan tidak puas.

Secara umum dari hasil analisis univariat, dari semua variabel, memiliki persepsi bahwa aspek mutu sangat penting dalam pelayanan rekam medis yang meliputi aspek keandalan, ketanggapan, jaminan, empati, dan bukti langsung. Hal ini dibuktikan bahwa kelima aspek memiliki nilai persentase di atas $50 \%$ untuk setuju. Selain itu, dari kelima aspek tersebut lebih dari $90 \%$ pasien sudah merasa puas terhadap pelayanan rekam medis.

\section{Analisis Bivariat}

Hasil analisis bivariat digunakan untuk mengetahui hubungan antara persepsi dengan tingkat kepuasan pasien tentang mutu pelayanan rekam medis. Analisis bivariat dilakukan dengan lima variabel dimensi mutu sebagai berikut: 
Tabel 11.

Hubungan Persepsi Keandalan dengan Tingkat Kepuasan Pasien tentang Mutu Pelayanan Rekam Medis

\begin{tabular}{llllllll}
\hline \multirow{2}{*}{$\begin{array}{l}\text { Persepsi } \\
\text { Keandalan }\end{array}$} & \multicolumn{6}{c}{ Kepuasan Keandalan } & \multirow{4}{*}{ p value } \\
\cline { 2 - 7 } & $\mathrm{n}$ & $\%$ & $\mathrm{~N}$ & $\%$ & $\mathrm{n}$ & $\%$ & \\
\cline { 2 - 6 } & 0 & 0 & 13 & 13 & 13 & 13 & \\
Tidak setuju & 6 & 6 & 27 & 27 & 33 & 33 & 0,116 \\
Biasa & 4 & 4 & 50 & 50 & 54 & 54 & \\
Setuju & & & & & 100 & 100 & \\
\hline Total & * & & & & &
\end{tabular}

Tabel 12.

Hubungan Persepsi Ketanggapan dengan Tingkat Kepuasan Pasien tentang Mutu Pelayanan Rekam Medis

\begin{tabular}{cccccccc}
\hline \multirow{2}{*}{$\begin{array}{c}\text { Persepsi } \\
\text { Ketanggapan }\end{array}$} & \multicolumn{9}{c}{ Kepuasan Ketanggapan } & \multirow{2}{*}{ p value } \\
\cline { 2 - 6 } & $\mathrm{n}$ & $\%$ & $\mathrm{~N}$ & $\%$ & $\mathrm{n}$ & $\%$ & \\
\hline Tidak Puas & 3 & 5 & 5 & 8 & 8 & \\
Biasa & 1 & 1 & 25 & 25 & 26 & 26 & 0,000 \\
Setuju & 1 & 1 & 65 & 65 & 66 & 66 & \\
\hline & \multicolumn{1}{c}{ Total } & & & & 100 & 100 & \\
\hline
\end{tabular}

*nilai $\mathrm{p}$ signifikan $(\mathrm{p}<0,05)$

Tabel 13.

Hubungan Persepsi Jaminan dengan Tingkat Kepuasan Pasien tentang Mutu Pelayanan Rekam Medis

\begin{tabular}{cccccccc}
\hline \multirow{2}{*}{$\begin{array}{c}\text { Persepsi } \\
\text { Jaminan }\end{array}$} & \multicolumn{6}{c}{ Kepuasan Jaminan } & \multirow{2}{*}{$p$ value } \\
\cline { 2 - 6 } & $\mathrm{n}$ & $\%$ & $\mathrm{~N}$ & $\%$ & $\mathrm{n}$ & $\%$ & \\
\cline { 2 - 7 } & 0 & 0 & 0 & 0 & 0 & 0 & \\
\hline Tidak setuju & 2 & 2 & 30 & 30 & 32 & 32 & 0,191 \\
Biasa & 1 & 1 & 67 & 67 & 68 & 68 & \\
Setuju & Total & & & & 100 & 100 & \\
\hline
\end{tabular}

*nilai $\mathrm{p}$ signifikan $(\mathrm{p}<0,05)$

Tabel 14

Hubungan Persepsi Empati dengan Tingkat Kepuasan Pasien tentang Mutu Pelayanan Rekam Medis

\begin{tabular}{|c|c|c|c|c|c|c|c|}
\hline \multirow{3}{*}{ Persepsi Empati } & \multicolumn{6}{|c|}{ Kepuasan Empati } & \multirow{3}{*}{$p$ value } \\
\hline & \multicolumn{2}{|c|}{ Tidak Puas } & \multicolumn{2}{|c|}{ Puas } & \multicolumn{2}{|c|}{ Total } & \\
\hline & $\mathrm{n}$ & $\%$ & $\mathrm{~N}$ & $\%$ & $\mathrm{n}$ & $\%$ & \\
\hline Tidak setuju & 0 & 0 & 6 & 6 & 6 & 6 & \\
\hline Biasa & 0 & 0 & 46 & 46 & 46 & 46 & 0,058 \\
\hline \multirow[t]{2}{*}{ Setuju } & 5 & 5 & 43 & 43 & 48 & 48 & \\
\hline & & & & & 100 & 100 & \\
\hline
\end{tabular}

*nilai $\mathrm{p}$ signifikan $(\mathrm{p}<0,05)$ 
Tabel 15.

Hubungan Persepsi Bukti Langsung dengan Tingkat Kepuasan Pasien tentang Mutu Pelayanan Rekam Medis

\begin{tabular}{|c|c|c|c|c|c|c|c|}
\hline \multirow{3}{*}{$\begin{array}{l}\text { Persepsi Bukti } \\
\text { Langsung }\end{array}$} & \multicolumn{6}{|c|}{ Kepuasan Bukti Langsung } & \multirow{3}{*}{$p$ value } \\
\hline & \multicolumn{2}{|c|}{ Tidak Puas } & \multicolumn{2}{|c|}{ Puas } & \multicolumn{2}{|c|}{ Total } & \\
\hline & $\mathrm{n}$ & $\%$ & $\mathrm{~N}$ & $\%$ & $\mathrm{n}$ & $\%$ & \\
\hline Tidak setuju & 0 & 0 & 6 & 6 & 6 & 6 & \\
\hline Biasa & 0 & 0 & 46 & 46 & 46 & 46 & 0,000 \\
\hline Setuju & 5 & 5 & 43 & 43 & 48 & 48 & \\
\hline Total & & & & & 100 & 100 & \\
\hline
\end{tabular}

Variabel keandalan, hasil dari uji chi square diperoleh $p$ value sebesar 0,116 >0,05, maka kesimpulannya adalah tidak ada hubungan antara persepsi keandalan dengan tingkat kepuasan pasien tentang mutu pelayanan di RSUD Ungaran. Hasil penelitian ini diketahui bahwa 90 responden yang menilai persepsi keandalan menyatakan puas dan 10 responden menyatakan tidak puas. Variabel keandalan merupakan kemampuan suatu rumah sakit khususnya Instalasi Rekam medis untuk menghasilkan pelayanan sesuai dengan apa yang dijanjikan.

Hasil dari penilaian pasien terhadap pelayanan khususnya variabel keandalaan antara lain waktu buka loket pendaftaran yang tepat waktu, pelayanan petugas yang cepat dan cekatan, komunikasi yang baik oleh petugas pelayanan, dan pemanggilan proses pelayanan dilakukan secara urut sesuai nomor antrian. Hasil penilaian, sebagaian besar puas terhadap pelayanan sehingga perlu dipertahankan aspek keandalannya.

Variabel ketanggapan, hasil dari uji chi square diperoleh $p$ value sebesar 0,000 $<0,05$, maka kesimpulannya adalah ada hubungan antara persepsi ketanggapan dengan tingkat kepuasan pasien tentang mutu pelayanan di RSUD Ungaran. Hasil penelitian ini diketahui bahwa 95 responden yang menilai persepsi ketanggapan menyatakan puas dan 5 responden menyatakan tidak puas. Variabel ketanggapan merupakan kemampuan rumah sakit khususnya Instalasi Rekam Medis untuk menghasilkan pelayanan yang baik dan tanggap.
Hasil penilaian pasien terhadap variabel ketanggapan antara lain petugas menyampaikan informasi dengan jelas, menggunakan bahasa yang mudah dimengerti, menawarkan bantuan ketika pasien merasa kebingungan, mendengarkan keluhan pasien, dan tanggap dalam membantu pasien.

Variabel jaminan, hasil dari uji chi square diperoleh $p$ value sebesar 0,191 >0,05, maka kesimpulannya adalah tidak ada hubungan antara persepsi jaminan dengan tingkat kepuasan pasien tentang mutu pelayanan di RSUD Ungaran. Hasil penelitian ini diketahui bahwa 97 responden yang menilai persepsi jaminan menyatakan puas dan 3 responden menyatakan tidak puas. Variabel jaminan merupakan kemampuan rumah sakit untuk menjamin kepada pasien bahwa rumah sakit mampu memberikan pelayanan yang baik.

Hasil penilaian pasien terhadap variabel jaminan antara lain keterampilan petugas, memahami pertanyaan dan keluhan pasien, kesopanan petugas, keramahan petugas, dan kesabaran petugas.

Variabel empati, hasil dari uji chi square diperoleh $p$ value sebesar 0,058 >0,05, maka kesimpulannya adalah tidak ada hubungan antara persepsi empati dengan tingkat kepuasan pasien tentang mutu pelayanan di RSUD Ungaran. Hasil penelitian ini diketahui bahwa 95 responden yang menilai persepsi empati menyatakan puas dan 5 responden menyatakan tidak puas. Variabel empati merupakan kemampuan rumah sakit dimana petugas mampu memberikan perhatian yang baik kepada pasien. 
Hasil penilaian pasien terhadap variabel empati antara lain pemberian salam oleh petugas kepada pasien, penerimaan yang baik oleh petugas, penawaran bantuan oleh petugas, pemberian kesempatan bertanya kepada pasien, dan ucapan terima kasih kepada pasien.

Variabel bukti langsung, hasil dari uji chi square diperoleh $p$ value sebesar 0,000 <0,05, maka kesimpulannya adalah ada hubungan antara persepsi bukti langsung dengan tingkat kepuasan pasien tentang mutu pelayanan di RSUD Ungaran. Hasil penelitian ini diketahui bahwa 94 responden yang menilai persepsi bukti langsung menyatakan puas dan 6 responden menyatakan tidak puas. Variabel bukti langsung merupakan kemampuan suatu rumah sakit dalam penyediaan sarana dan prasarana yang memadai kepada pasien. Hasil dari penilaian pasien terhadap variabel bukti langsung antara lain penyediaan papan informasi, papan alur, jumlah tempat duduk, penyediaan tempat sampah, penyediaan $\mathrm{AC}$, penyediaan televisi, pakaian petugas yang rapi, serta bersih.

\section{Simpulan dan Saran \\ Simpulan}

Terdapat hubungan antara persepsi ketanggapan dan bukti langsung dengan tingkat kepuasan pasien tentang mutu pelayanan rekam medis. Tidak ada hubungan yang signifikan antara persepsi keandalan, jaminan, dan empati dengan tingkat kepuasan pasien tentang mutu pelayanan rekam medis.

\section{Saran}

Pada variabel keandalan perlu mempertahankan dan meningkatkan aspek kualitas layanan petugas kepada pasien. Pada variabel bukti langsung perlu meningkatkan kemampuan dan sikap petugas dalam melayani pasien. Pada bagian variabel empati peran petugas yang memahami pasien sangat penting.

\section{Ucapan terimakasih}

Terima kasih kepada Direktur Poltekkes Kemenkes Semarang, DIPA Poltekkes Kemenkes Semarang yang telah mendanai penelitian ini, Tim penyusun penelitian dan semua pihak yang terlibat dalam penelitian ini.

\section{Daftar Pustaka}

Adisasmito, W. 2012. Sistem Kesehatan. Jakarta: Rajawali Pers.

Arikunto, S. 2006. Prosedur Penelitian Suatu Pendekatan Praktik. Jakarta: Rineka Cipta.

Hatta, G. R, 2013. Pedoman Manajemen Informasi Kesehatan di Sarana Pelayanan Kesehatan. Jakarta: UI Press.

Hasbi, Fiil Hendra. Analisis Hubungan Persepsi Pasien tentang Mutu Pelayanan dengan Pemanfaatan Ulang Pelayanan Rawat Jalan Puskesmas Poncol Kota Semarang Tahun 2012.Jurnal Kesehatan Masyarakat.Vol.1 No.2 . diakses pada tanggal 19 Februari 2018 dari http://ejournals1.undip.ac.id/ index.php/jkm

Indradi, Rano. (2013). Rekam Medis. Tangerang Selatan: Universitas Terbuka.

Jogiyanto. (2014). Pedoman Survey Kuesioner. Cetakan ke-4. BPFE. Yogyakarta.

Muninjaya, Gde. Manajemen Mutu Pelayanan Kesehatan. Jakarta: EGC.

Keputusan Menteri Kesehatan Republik Indonesia Nomor: 129/Menkes/SK/II/2008 Tentang Standar Minimal Rumah Sakit.

Keputusan Menteri Kesehatan Republik Indonesia Nomor: 377//Menkes/SK/III/2007 Tentang 
Standar Profesi Perekam Medis Dan Informasi Kesehatan.

Muninjaya, G. 2014. Manajemen Mutu Pelayanan Kesehatan.Jakarta: EGC.

Notoatmodjo, Soekidjo. (2012). Metodologi Penelitian Kesehatan. Jakarta: Rineka Cipta.

Pohan, Imbalo S. (2006). Jaminan Mutu Layanan Kesehatan. Jakarta: EGC.

Rustiyanto, Ery. (2012). Etika Profesi Perekam Medis dan Informasi Kesehatan. Yogyakarta: Graha Ilmu.
Satrianegara, Fais. (2014). Organisasi dan Manajemen Pelayanan Kesehatan. Jakarta: Salemba Medika.

Sugiyono. (2008). Metode Penelitian Kuantitatif, Kualitatif dan $R \in \mathcal{E} D$. Bandung: Alfabeta.

Sunyoto, D., Setiawan, A. (2013). Buku Ajar: Statistik Kesehatan Parametrik, Non Parametrik, Validitas dan Reliabilitas. Yogyakarta: Nuha Medika.

Supranto. (2011). Pengukuran Tingkat Kepuasan Pelanggan. Jakarta: Rineka Cipta. 